\title{
Regarding "Percutaneous Antegrade Colonic Stent Insertion Using a Proximal Trans-peritoneal Colopexy Technique"
}

\author{
Yahua $\mathrm{Li}^{1} \cdot$ Xinwei $\operatorname{Han}^{1}$ (D)
}

Received: 10 July 2018/Accepted: 14 July 2018/Published online: 24 July 2018

(C) Springer Science+Business Media, LLC, part of Springer Nature and the Cardiovascular and Interventional Radiological Society of Europe (CIRSE) 2018

We read with great interest the recent article by Kawa et al [1]. The author reported three patients who received percutaneous antegrade colonic stent insertion using a proximal trans-peritoneal colopexy technique, which conventional stenting has failed/is unsuitable.

Stenting under the guidance of fluoroscopy or endoscopy has its own advantages and disadvantages. An endoscopist who experiences a colonoscopy and fluoroscopy performs SEMS placement successfully regardless of the level of experience [2]. The combination of the two would improve the technical success rate. In the research of Bekheet [3] and his colleagues, six of 15 patients who failed to place a stent with fluoroscopy were successfully placed with the combination of endoscopy and fluoroscopy. Kobayashi et al. [4] report the application of ultra-thin endoscopy and fluoroscopy in right-sided colonic stenosis which is difficult to manage with single traditional technique.

We would like to recommend the combination of endoscopy and fluoroscopy first and then the anterograde stenting. After all, percutaneous antegrade colonic stent insertion has potential complication of stoma formation.

\section{Compliance with Ethical Standards}

Conflict of interest The authors indicate no potential conflicts of interest.

Ethical Approval This article does not contain any studies with human participants or animals performed by any of the authors.

\section{References}

1. Kawa B, Thomson B, Rabone A, et al. Percutaneous antegrade colonic stent insertion using a proximal trans-peritoneal colopexy technique. Cardiovasc Intervent Radiol. 2018. https://doi.org/10. 1007/s00270-018-2002-4.

2. Lee HJ, Park SJ, Cheon JH, et al. What is the necessity of endoscopist for successful endoscopic stenting in patients with malignant colorectal obstruction? Int $\mathrm{J}$ Colorectal Dis. 2014;30(1):119-25.

3. Bekheet N, Kim MT, Park JH, et al. Fluoroscopic gastroduodenal stent placement in 55 patients with endoscopic stent placement failure. Cardiovasc Intervent Radiol. 2018;41(8):1233-40.

4. Kobayashi Y, Komazawa Y, Kusunoki M, et al. Novel stenting method for malignant right colonic stenosis using ultra-thin endoscopy: report of four cases. Dig Endosc. 2015;27(6):704-7.
Xinwei Han

hanxinwei2006@163.com

Yahua Li

liyahua1990@163.com

1 Department of Interventional Radiology, The First Affiliated Hospital of Zhengzhou University, Zhengzhou 450052, China 